\title{
Climate change and winter road maintenance
}

\section{Torbjørn Lorentzen ${ }^{1}$}

Received: 20 May 2019 / Accepted: 16 January 2020/ Published online: 31 January 2020

(C) The Author(s) 2020

\begin{abstract}
The objective of the article is to analyse the impact of short- and long-term climate variations on the costs of removing snow and ice from the roads in Bergen - the second most populous city in Norway. The analysis applies simple mathematics, Monte Carlo simulations and multivariate regression methodology. The municipality of Bergen manages about $630 \mathrm{~km}$ of roads and $100 \mathrm{~km}$ of foot and bicycle paths, and the municipal administration spends NOK 37 million (or about USD 4.5 million) annually on removing snow and ice during the winter period. The analysis shows that a $1{ }^{\circ} \mathrm{C}$ increase in the mean temperature reduces the winter maintenance costs by NOK 14 million, and it is likely that there will be no need for winter snow-clearing operations if the long-term mean atmospheric temperature increases by approximately $2.5^{\circ} \mathrm{C}$ or more relative to the historical mean temperature level. The analysis shows that the variance and trend of the temperature have a strong effect on the likelihood of a snow- and ice-free winter and that a long-term reduction in the variance reduces the likelihood of rare events even though the mean temperature increases. The analysis provides the municipality of Bergen with information about the relationship between climate and winter road maintenance costs, and the statistical models can help to quantify the amount of economic and material resources needed for this purpose. The analysis is a contribution in the field of economic impact analysis of climate change on the transport sector.
\end{abstract}

Keywords Winter road maintenance costs $\cdot$ Climate change $\cdot$ Statistical analysis $\cdot$ Monte Carlo simulations $\cdot$ Return period

\section{Introduction}

Bergen City is located at the west coast of Norway and northern Europe $\left(60^{\circ} 23^{\prime} \mathrm{N}, 005^{\circ} 19^{\prime} \mathrm{E}\right.$. See Online Resource Fig. 1). Bergen Municipality is responsible for maintaining approximately

Electronic supplementary material The online version of this article (https://doi.org/10.1007/s10584-02002662-0) contains supplementary material, which is available to authorized users.

Torbjørn Lorentzen

torbjorn.lorentzen@hvl.no; tobbenlorentzen@gmail.com

1 Western Norway University of Applied Sciences, Inndalsveien 28, 5063 Bergen, Norway 
$630 \mathrm{~km}$ of carriageways and $102 \mathrm{~km}$ of foot and cycle paths (Bergen Municipality, 2016). During the winter season, snow and ice are removed from the roads to keep the infrastructure open for traffic. The expenses associated to these operations are in the public budget defined as winter operation costs. The municipality spent on average NOK 37 million per year on winter operations (2015 value). During the period 2005-2015, Bergen Municipality spent in total NOK 407 million or approximately USD 4.5 million, given an exchange rate of NOK 9 per USD (Norges Bank 2019) on these operations diring the winter season. Weather conditions play a decisive role for the extent of snow and ice on the roads and thus for resources needed to keep the roads open for normal and safe traffic. The Traffic department of the Bergen Municipality organizes the winter operations and outsources most of the operations to private firms.

Bergen Municipality has a population of about 280,000 of whom 166,000 are travelling daily to work (2018 values), and goods and services are transported from suppliers to customers inside and outside the region. It is important that the infrastructure is available for use $24 \mathrm{~h}$ a day. If snow and ice are not removed, transportation and most of the activities in the region of Bergen will be delayed and, in the worst-case, hindered, especially if transport related to emergencies is involved. In addition, insufficient road maintenance in the winter season is likely to increase the frequency of traffic accidents and fatalities (Koetse and Rietveld 2009; Andersson and Chapman 2011a, 2011b).

The objective of the article is to analyse to what extent variation in climate conditions affects the maintenance costs of roads during the winter season in Bergen. The aim is to measure how the variation in temperature and precipitation affect the level of winter road maintenance costs in the short and long term. Long-term (multidecadal) global warming and short-term (yearly) natural variation in the climate actualizes this type of analysis. By using available instrumental data, it is possible to analyse the connection between climate conditions and winter operation costs. The article analyses the following issues: Is there any covariation between climate conditions and the costs of clearing the roads of snow and ice? How will the temperature develop in the short and long term, and will such temperature changes affect the costs of winter operations? How likely is it that Bergen in the future will experience a snowand ice-free winter and thus very low winter maintenance costs?

There is a considerable amount of literature in the field of climate variation and impact on the social conditions, economy and the environment (IPCC 2014; Stern 2006). As an example, Hitz and Smith (2004) show how a general increase in the global mean temperature affects different sectors of the economy. The authors show that a marginal increase in the global mean temperature relative to the 1990 level may have a beneficial impact on some sectors such as agriculture and forestry, but that an increase in the mean temperature of $3-4{ }^{\circ} \mathrm{C}$ will have negative consequences on society and the natural environment. An updated analysis of Tol (2018) draws a similar conclusion. The climate summit in Paris in 2015 concluded that it is necessary to pursue a policy that overall contributes to holding the increase in the global temperature well below $2{ }^{\circ} \mathrm{C}$ above pre-industrial levels to prevent serious risk exposure and impacts of climate change (United Nations 2015, p. 3 Paris Agreement).

Literature search on the subject "climate and transport" shows that analyses in this field focus mainly on how climate change affects airports, power networks, rail networks, roads, public buildings, water quality and supply and sewage: Larsen et al. (2008) find that climate change increases wear and tear on roads in Alaska by between 10 and 20\% relative to normal, past conditions. Other analyses focus on how climate change affects road traffic accidents and the number of fatalities. IPCC's Fifth Assessment Report (Working Group II) refers to several scientific publications that analyse how climate change and sea level rise affect transport and 
infrastructure. Sherif and Hassan (2014) estimate a linear model to predict the pavement surface temperature which is applied as an indicator in the planning of winter operations on roads on a daily time scale. Hanbali (1994) uses a cost-benefit analysis to show that the socioeconomic benefit of keeping the roads open and ensuring normal winter traffic is significantly larger than the costs of not removing snow and ice from roads and pavements (see also Arent et al. 2014).

The remaining part of the article is structured as follows. The second section presents the methods and variables applied in the analysis. The third section estimates the relationship between climate and winter operating costs. The fourth section analyses the short- and longterm development of the temperature in the region of Bergen. This section derives a model applied in analysing how the likelihood of snow-free winter in Bergen is influenced by climate change. The fifth part uses Monte Carlo simulations to show how the long-term climate projections for western Norway affect the future winter operations in Bergen by 2100. The last, sixth, section summarizes the analysis.

\section{Methodology}

The following methodologies are applied in the analysis: Descriptive statistics measure the location and spread of the variables included in the analysis, while estimation of Pearson's correlation coefficient gives a rough measure of the instantaneous relationship between the entities. Linear regression is applied in estimating the causal relationship between costs and climate variables. The validity of the regression models is evaluated by testing the statistical properties of the residuals with respect to the degree of autocorrelation, degree of stability of the variance and whether they are normally distributed. Multicollinearity measures are applied in evaluating the degree of correlation between independent variables included in the regression model. Special test procedures are also applied: model specification tests of function form, stability tests of estimated coefficients and tests of comparing different models. Unit root testing for stationarity of the time series is applied. Quantile regression is applied in the evaluation of the long-term development of the spread of the temperature. Estimation of autoregressive conditional heteroscedasticity models $(\mathrm{ARCH})$ is applied in analysing whether the volatility of the temperature is conditioned on historical variation. Monte Carlo simulations are applied to illustrate the likely short- and long-term changes in temperature and the potential effect on road maintenance costs. Simple mathematics is applied in formalizing how long-term changes in climate influence on the likelihood of rare events in the region of Bergen. References for formal description of tests and estimation methods are included in the text where they are applied.

\subsection{Definition of variables}

The winter road maintenance costs are measured as an aggregate of, respectively, the direct costs of removing snow and ice from the roads, salting, car hiring, input of raw materials and labour costs. The cost data are not sorted by type of infrastructure, i.e. pathway or road, and the analysis does not take into consideration that climate change is expected to change the indirect costs associated to changes in travel time, frequency of accidents, road crashes and deaths rate on the roads. To compare expenses over time, the expenditures are adjusted to 2015 values by the consumer price index (CPI) obtained from Statistics Norway. The winter operation costs 
are registered in January, February, March and April and in the autumn and winter months October, November and December. In total, the winter period includes 7 months. Temperature data included in the analyses are the average of the 7 months where the winter maintenance takes place each year in the period 2005-2015. Precipitation data are the sum of the 7 months. In the estimation of the theoretical return period (waiting time) of a rare year without snow and ice on the roads and no maintenance costs, local temperature series from two periods, respectively, the period 2005-2015 and the period 1916-2015 are used. The analysis applies also regional temperature trend projections made by Norwegian scientists in climatology (Hanssen-Bauer et al. 2015, 2017). The climate variables included in the analysis are official data, measured at the Florida weather station in Bergen by the Norwegian Meteorological Institute n.d. (www. eKlima.no or www.met.no). The Traffic division at Bergen Municipality provides the aggregated yearly cost data related to the referred winter operations for the period 2005-2015.

Figure 1 shows how costs, winter temperature and precipitation have developed for the seven winter months per year in the period 2005-2015. The annual mean cost of winter operations is NOK 37 million (2015-value). The minimum and maximum costs are respectively NOK 20 and NOK 92 million. The maximum cost was measured in 2010, and it was the coldest year this period with an average of $1.7^{\circ} \mathrm{C}$ and the year with the lowest level of precipitation. The lowest level of costs was in 2006. The maximum precipitation level was in 2015, and the maximum temperature was in 2014 (see Table 1 Online Resource). A large part of the road maintenance decisions is based on weather forecasts. The municipality must mobilize and spread sand and salt to be ahead of expected snowfall and ice. If the forecast fails, there occurs a discrepancy between the weather forecast-conditioned actions and what in the aftermath was necessary to do. On average, Bergen spends about NOK 59 per meter road in winter operating costs per year. If the length of foot and cycle paths is included, the winter operating costs amount to NOK 50.5 per meter (2015 value). Bergen set a new, all-time-high annual precipitation record of $3100 \mathrm{~mm}$ in 2015 (www. eKlima.no). Note that the record includes all 12 months of the year.

\section{Regression model}

Figure 1 indicates that there is a strong inverse relationship between winter operating costs and temperature, and it is also visual that temperature and rainfall follow the same pattern. Evaluation of the variables shows that neither of them has a trend, and they are level stationary processes in the relatively short window the data cover.

Pearson's correlation coefficient shows a significant correlation between the variables (twosided test and 5\% significant level. See Online Resource Fig. 2). The correlation is strongest between costs and temperature. Although the correlation-measure does not indicate the direction of causality between the variables, it is still apparent. The direction of cause and effect is as follows: Temperature and precipitation affect the snow and ice conditions, and not vice versa and it implies that these variables are exogenous to winter maintenance costs. There is no time lag between the variables, between stimuli and response, i.e. the snow that fell last year is not removed from the roads next year. The statistical models applied in the analysis are therefore static. Two models are estimated to measure the relationship between temperature, precipitation and winter operating costs. Model 1 is as follows (Eq. 1): 

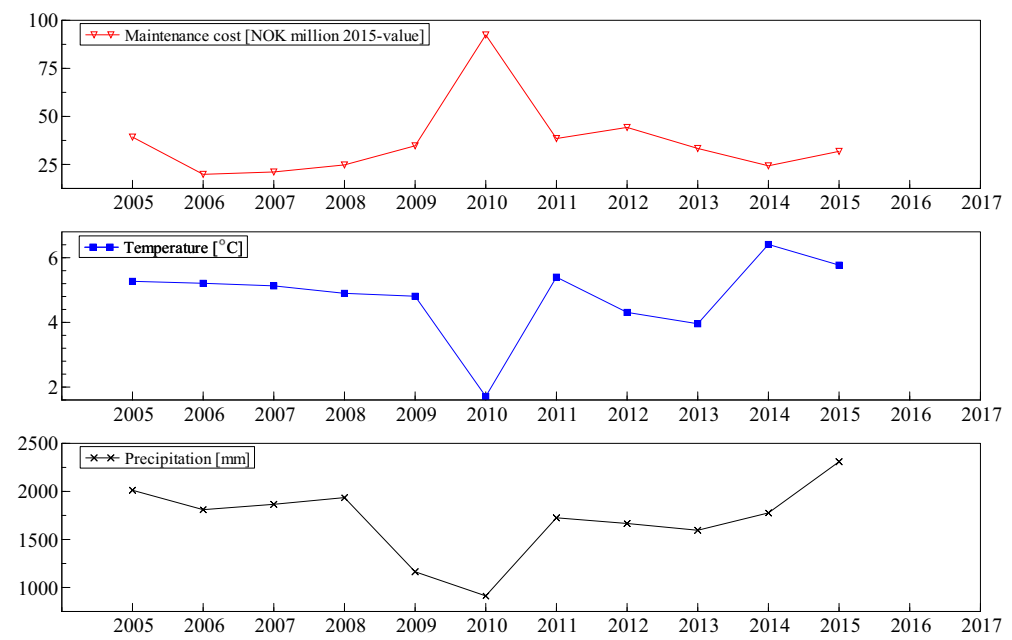

Fig. 1 The uppermost graph shows the winter operation costs, the middle graph shows the mean temperature, and the lowermost graph shows the precipitation. The series cover only the 7 months of the year (the "winter period") where the winter maintenance takes place. The curves cover the period 2005-2015. Source: Bergen Municipality and the Norwegian Meteorological Institute

$$
C_{t}=\alpha+\beta_{1} x_{1 t}+\beta_{2} x_{2 t}+\varepsilon_{t},
$$

where $C_{t}$ : winter operating costs at time $t=2005, \ldots, 2015, x_{1 t}$ : mean temperature $\left({ }^{\circ} \mathrm{C}\right)$, $x_{2 t}$ : total rainfall $(\mathrm{mm})$ and $\varepsilon_{t}$ : residual which measures the unexplained variation in the dependent variable. The residuals are independently, normally distributed and with constant variance. $\alpha, \beta_{1}$ and $\beta_{2}$ are the coefficients in the model that are estimated by ordinary least squares method (OLS). Table 1 shows the result of the estimation. Evaluation of the estimated model shows that there is no first (Durbin-Watson test score is 1.49) or higher order autocorrelation between the residuals. The residuals are normally distributed; Jarque-Bera chi-square test score is 1.34 and $p$ value $=0.51$ (Jarque \& Bera 1981) and White's test indicates that the variance is constant (White 1980). Ramsey RESET test returns specification problems associated with the model (Ramsey 1969), and Hansen's test indicates that there are no structural changes either in the coefficients or the variance of the residuals (Hansen 1992). The multiple correlation coefficient $R^{2}=0.73$, indicating that the model explains $73 \%$ of the variation in the winter costs. Figure 1 shows that temperature and precipitation is almost a mirror image of each other. The Clausius-Clapeyron equation (Iribarne and Godson 2013) formalizes the relationship between air temperature and the atmosphere's ability to hold water. See e.g. Sørland 2015 who demonstrates empirically the relationship. Model I can be simplified due to the high correlation between temperature and precipitation $(\rho=0.67$ and $p$ value $=0.023)$ which generates multicollinearity (Wichers 1975) and inflates the variance of the coefficient estimates. Precipitation is excluded from Model 1. AIC, Akaike Information Criterion (Akaike 1973), indicates that the simplified model is the best model. The AIC score of the simplified model is 4.98, while the AIC of the original model (Model 1) is 5.14. Table 2 presents the result of the estimation of the simplified model (Model 2).

Model 2 has the same explanatory power as Model 1, i.e. $R^{2}=0.73$. The estimated coefficient of the temperature variable is slightly larger than the estimated coefficient in 
Model 1, and compared to the first model, the variance of the coefficients is lower. The estimated model shows that temperature and the constant term are both significantly different from zero. The coefficient of the temperature variable is $\beta_{1}=-14.017$ ( $p$ value $\left.=0.001\right)$, and it follows that an increase in the mean winter temperature by $1{ }^{\circ} \mathrm{C}$ is expected to reduce the winter operating costs by NOK 14.0 million. The estimated elasticity around the mean values (see Table 2) shows that a $1 \%$ increase in temperature reduces the costs by $1.8 \%$. Figure 2 shows the estimated and observed development of costs of maintenance from 2005 to 2015 . In summary, the estimated model shows that temperature has a clear effect on the costs of road maintenance. The result of the estimation is applied in the following section where the likelihood of a snow- and ice-free winter is calculated and in the last section where the future costs of road maintenance are simulated.

\section{What is the probability of a snow- and ice-free winter in Bergen?}

Model 2 is applied in calculating the rare, critical temperature level that causes winter costs to be approximately zero. Model 2 estimates the cost function $C=104.13-14.02 x$, and the average winter operating costs are approximately zero at some time point in the future when the temperature approaches $104.13 / 14.02 \approx 7.43{ }^{\circ} \mathrm{C}$ or higher. During the period $2005-$ 2015, the calculated, overall mean temperature is $4.81{ }^{\circ} \mathrm{C}$. According to model 2 , if the mean temperature increases by $\Delta x_{1}=7.43-4.81=2.62^{\circ} \mathrm{C}$ or more, the winter operating costs are approximately zero. Formally, the increase implies that the statistical distribution shifts by 2.62 .

How can a significant change $\left(\Delta x_{1}\right)$ in temperature be modelled? Based on observational data for the period 2005-2015, the overall mean and standard deviation of the winter temperature are calculated to 4.81 and $1.22{ }^{\circ} \mathrm{C}$, respectively. How likely is it that the temperature in a random, single year is close to the $7.43{ }^{\circ} \mathrm{C}$ level or higher? Autocorrelation function $(\mathrm{ACF})$ shows that the observations are independently distributed. The Jarque-Bera test $(p$ value $=0.06)$ and Lilliefors test $(p$ value $=0.11)$ cannot reject that the observations are normally distributed, and the problem can be analysed by using the normal distribution. On the other hand, if the time series had extreme temperature levels and fat tails, it has been relevant to apply the "general extreme value theory" (GEV) in the estimation of return periods of extreme temperature levels (Reiss and Thomas 2001). It can be shown, by using the standard normal distribution, that the likelihood that the temperature, of a random winter, will be higher or equal to $7.43{ }^{\circ} \mathrm{C}$ is $P(z \geq 2.148)=0.016$. The critical $z$ value (number of standard deviation) is calculated as follows: $z=\frac{7.43-4.81}{1.22}=2.148$. The result shows that the probability of the marginal, rare event is 0.016 . The estimate is applied in calculating the waiting time for an observation where the temperature is $7.43{ }^{\circ} \mathrm{C}$ or higher, and in this case the waiting time is

Table 1 Estimated model 1. Winter operating costs are the dependent variable. Based on data for the period 2005-2015

\begin{tabular}{lllrlrr}
\hline $\begin{array}{l}\text { Variable } \\
\text { name }\end{array}$ & $\begin{array}{l}\text { Estimated } \\
\text { coefficient }\end{array}$ & Standard error & $T$ ratio & $p$ value (8 DF) & $\begin{array}{l}\text { Partial } \\
\text { correlation }\end{array}$ & $\begin{array}{l}\text { Elasticity at } \\
\text { means }\end{array}$ \\
\hline Temperature & -12.716 & 4.569 & -2.783 & 0.024 & -0.701 & -1.663 \\
Precipitation & -0.0055 & 0.0145 & -0.380 & 0.714 & -0.133 & -0.255 \\
Constant & 107.25 & 17.06 & 6.287 & 0.000 & 0.912 & 2.918 \\
\hline
\end{tabular}


Table 2 Estimated model 2. Winter operating cost is the dependent variable. Based on data for the period 20052015

\begin{tabular}{lccrrrr}
\hline Variable name & $\begin{array}{l}\text { Estimated } \\
\text { coefficient }\end{array}$ & Standard error & $T$ ratio & $\begin{array}{l}p \text { value } \\
(9 \text { DF })\end{array}$ & $\begin{array}{l}\text { Partial } \\
\text { correlation }\end{array}$ & $\begin{array}{l}\text { Elasticity at } \\
\text { means }\end{array}$ \\
\hline Temperature & -14.017 & 2.877 & -4.873 & 0.001 & -0.852 & -1.8334 \\
Constant & 104.130 & 14.23 & 7.319 & 0.000 & 0.925 & 2.8334 \\
\hline
\end{tabular}

about 63 years $(1 / 0.016=62.5)$, given the information embedded in the time series covering the period 2005-2015. This means that within a period of over 60 years, there is a theoretical possibility that the winter costs in Bergen can be approximately zero, given a standard deviation of 1.22. The calculation assumes that future temperature has identical statistical characteristics measured in the period 2005-2015. It implies that future temperature varies stochastically and independently around a mean value of $4.81{ }^{\circ} \mathrm{C}$ with a constant standard deviation of $1.22{ }^{\circ} \mathrm{C} /$ year. However, the assumption of identical statistical properties is not valid if the temperature follows a new trajectory or pattern due to man-made global warming or as a result of long-term, natural climate variation. Long-term changes will change the statistical distribution and the probability distribution of the realization of temperature and precipitation. The following two sub-sections analyse the likely future development of the temperature level in the region of Bergen. A projection of the future development will inform how strongly the winter operation costs can be affected.

\subsection{What is the expected future temperature level?}

According to Working Group I (WGI) of IPCC's assessment report (IPCC 2014), the global mean temperature is expected to increase in the future, but it is uncertain how much and how fast it will increase, and the changes will not be equal between regions. See for example Iversen et al. (2013) who show the geographical distribution of the expected changes in mean annual surface temperature under different RCP-scenarios. RCP is an abbreviation for "Representative Concentration Pathways" and it refers to different climate gas concentration trajectories and the associated net increase in radiative forcing (watts per square meter per unit of time) by about 2100 relative to pre-industrial time.

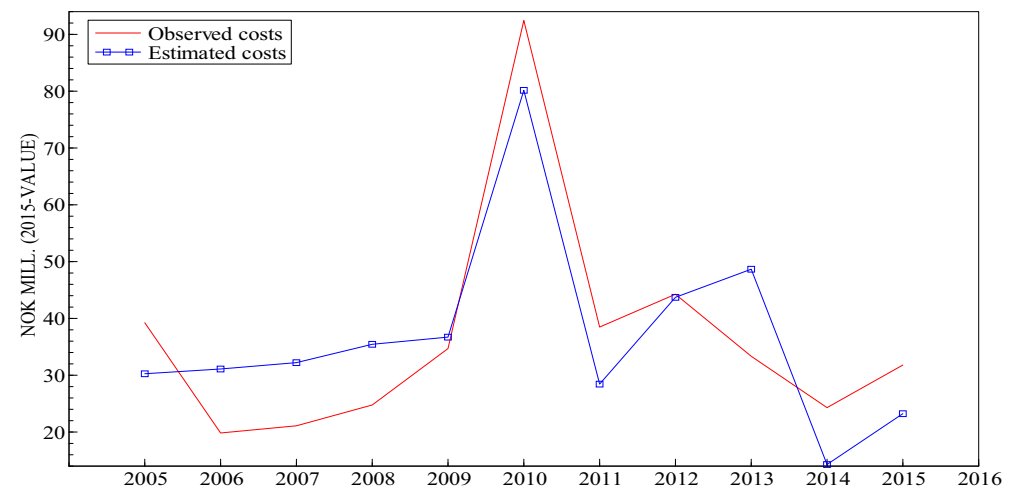

Fig. 2 Observed (red line) and estimated winter operating costs, based on model 2, for the period 2005-2015 
An expert group of Norwegian climate scientists has recently concluded that the autumn and the winter temperature in western Norway, including the region of Bergen, will increase in the future between 1.3 and $5.2{ }^{\circ} \mathrm{C}$ by 2100 relative to the reference period 1971-2000 (Hanssen-Bauer et al. 2015, pp. 145 and 153, Tables A.5.1.1 and A.5.1.2, p. 153 and Hanssen-Bauer et al. 2017, Table 3.2, p. 17). The size of the temperature increase is critically depending on the emission scenario. The estimates follow from the minimum scenario in RCP4.5 and the maximum scenario in RCP8.5, respectively. If the projected time horizon is shorter, Hanssen-Bauer et al. (2015, Table A.5.2.3, p. 151), conclude that the temperature in the autumn and winter months (average of the medians) in western Norway may increase between 1.65 and $2.35{ }^{\circ} \mathrm{C}$ by 2060 . The lowest estimate is based on the RCP2.6 scenario and the largest temperature increase is based on the RCP8.5 scenario. Stine and Huybers (2012) and McKinnon et al. (2013) show that winters will warm more than summers. Stine et al. (2009) analysed data from the Northern Hemisphere covering the period 1900-2007. They conclude that the annual cycle has changed, and it implies warmer winters due to, respectively, seasonal phase shifting to earlier dates, reduction in the seasonal amplification (the difference between summer and winter temperatures) and increasing average temperature. Park et al. (2018) analysed the period 1953-2012 and conclude that the length of the summer season has significantly increased in the Northern Hemisphere and its subregions. Førland et al. (2004) applied historical and climate model-generated data covering the period 1900-2050 and conclude that the growing season in Norway has significantly increased, and it will continue to increase.

These findings indicate that the longer the summer season is, the shorter is the winter season and the temperature in the winter season is expected to increase. If the mean temperature increases, it will result in milder winters, and thus, in the long-term, it is likely that it will reduce the need for winter maintenance capacity.

\subsection{Development of the local winter temperature level}

The following subsection looks closer on how the local temperature in the winter period has developed from past to the present. The estimated cost-temperature model uses data covering the period 2005-2015. It was not possible to identify any overall trend in the time series of this relatively short time period. The time window is too small in order to measure long-term changes in the data. Local observational data for the period 1916-2015 are applied in analysing the properties of the winter temperature. Figure 3 shows, respectively, the yearly historical winter temperature (red line), a smoothed version of the series (blue line) and the linear, deterministic trend line derived from the regression model presented in Table 3.

Visual inspection of the smoothed series gives the impression that the winter temperature has developed in the following three stages: (1) temperature increases in the period 19161934, (2) temperature oscillates around a relatively fixed level during the period 1940-1980 and (3) temperature increases in the period 1980-2015, but note that it did not measure any significant temperature trend in the period 2005-2015. The series, and the smoothed series, shows that temperature is oscillating, and the periodogram indicates clearly that the length of the period is between 7 and 8 years with an amplitude of $0.52{ }^{\circ} \mathrm{C}$ which shows that warm/coldwinter recurs every 7-8 years (Fisher's kappa $=8.12 p$ value $=0.008$ ). The difference in trend is partly explained by the fact that temperature varies on multidecadal scale on top of the longterm trend, and partly that trend estimates based on different time windows, will not be equal. This point is mentioned in IPCC's Fifth Assessment Report (IPCC 2014, WGI, p. 2). The 


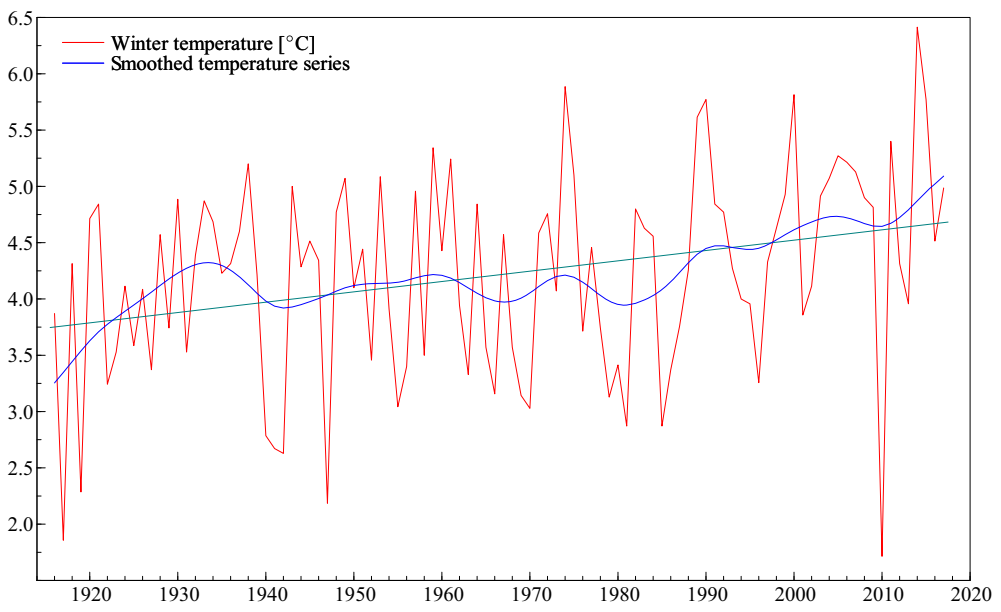

Fig. 3 Yearly historical winter temperature (red line) in Bergen, smoothed series (blue line), and the linear trend line (grey line) derived from the regression model presented Table 3

stepwise-like development of the temperature could correspond to the so-called "hiatus"phenomenon detected in the period 1998-2012 (Medhaug et al. 2017). A stepwise pattern is also measured in sea temperature along the coast of Norway (Lorentzen 2014). Even though it is a stepwise development, an augmented Dickey-Fuller test (Dickey \& Fuller 1979) cannot reject that the temperature series is a trend-stationary process. A linear regression model is applied in estimating the development of the local winter temperature. The regression model includes a constant and a deterministic trend variable. Table 3 shows the result of the estimation.

The estimation shows that the winter temperature on average has increased by about $0.0091{ }^{\circ} \mathrm{C} /$ year. Evaluation of the estimated model shows that there is no first $(\mathrm{DW}=1.81)$ or higher order autocorrelation between the residuals. The residuals are normally distributed (Jarque-Bera chi-square test score is 4.54 and $p$ value $=0.10$ ) and White's test indicates that the variance is constant, which means that there is no heteroscedasticity. Ramsey RESET test returns no problems associated with the specification of the model even though the smoothed series is characterized by three stages in the development of the temperature. Nor does the Hansen's test indicate any structural changes either in the coefficients or the variance, given $5 \%$ level, but the null hypotheses of stable variance and coefficients are close to being rejected. The result of Hansen's test could be an indication of a fragile model and that the temperature follows a non-linear process. The estimated regional temperature trend corresponds to Luterbacher et al. (2004) who estimated an overall significant linear trend of $0.008{ }^{\circ} \mathrm{C} /$ year in the atmospherically land winter temperature in Europe for the period 1901-2000.

Table 3 Estimation of temperature trend in the winter period 1916-2015

\begin{tabular}{lllllll}
\hline $\begin{array}{l}\text { Variable } \\
\text { name }\end{array}$ & $\begin{array}{l}\text { Estimated } \\
\text { coefficient }\end{array}$ & $\begin{array}{l}\text { Standard } \\
\text { error }\end{array}$ & $T$ ratio & $\begin{array}{l}p \text { value }(98 \\
\text { DF) }\end{array}$ & $\begin{array}{l}\text { Partial } \\
\text { correlation }\end{array}$ & $\begin{array}{l}\text { Elasticity at } \\
\text { means }\end{array}$ \\
\hline Time & 0.00909 & 0.003041 & 2.988 & 0.004 & 0.289 & 0.1092 \\
Constant & 3.7450 & 0.1769 & 21.17 & 0.000 & 0.906 & 0.8908 \\
\hline
\end{tabular}




\subsection{Climate change and the likelihood of a snow- and ice-free winter}

This section derives the model applied in analysing how potential, long-term changes in climate can affect the probability that the winter temperature approaches and crosses a "critical" level $x_{\mathrm{c}}$. Assume that $x_{\mathrm{c}}$ is the temperature level that does not trigger winter operations. A level stationary, normally distributed variable at time point $t$ can be fully described by the expected value $\mu(t)$ and the standard deviation $\sigma(t)$. Standardization of a normally distributed variable can be expressed as follows (Eq. 2):

$$
z(t)=\frac{x_{\mathrm{c}}-\mu(t)}{\sigma(t)}
$$

Suppose that both the variance and the expected value of temperature change over time. It implies that the first two moments of the statistical distribution of temperature are functions of time. When the moments change or shift over time, the properties of the distribution of the temperature also change. Assume that $z(t)$ is continuous and differentiable with respect to time $t$ and that the critical value $x_{\mathrm{c}}$ is a constant and does not change over time. A marginal change in the moments with respect to time induces the following effects on the distribution of the standardized $z(t)$ variable (Eq. 3):

$$
\frac{\partial z(t)}{\partial t}=\left[\left[\mu(t)-x_{\mathrm{c}}\right] \frac{\partial \sigma(t)}{\partial t}-\frac{\partial \mu(t)}{\partial t} \sigma(t)\right] \frac{1}{[\sigma(t)]^{2}}
$$

The expression may be positive, negative or zero depending on the direction and strength of the changes of the moments $[\sigma(t)$ and $\mu(t)]$ and the level of the critical value $x_{\mathrm{c}}$. In this context, it is consistent to expect that $\mu(t)-x_{\mathrm{c}}<0$ and $\frac{\partial \mu(t)}{\partial t}>0$ due to the observed positive temperature trend. Assume that the standard deviation is increasing or constant, i.e. $\frac{\partial \sigma(t)}{\partial t} \geq 0$, and the variance is always positive $\sigma^{2}>0$. If these conditions are fulfilled, it follows that $\left[\mu(t)-x_{\mathrm{c}}\right]$ $\frac{\partial \sigma(t)}{\partial t}-\frac{\partial \mu(t)}{\partial t} \sigma(t)<0$ and $\frac{\partial z(t)}{\partial t}<0$. Further, if $\frac{\partial z(t)}{\partial t}<0$, it follows that the statistical distribution changes in a direction that increases the likelihood of observing temperature approaching $x_{\mathrm{c}}$ over time. The last condition can be reformulated and expressed as $\frac{\frac{\partial \sigma(t)}{\sigma(t)}}{\sigma(t)}\left[\mu(t)-x_{\mathrm{c}}\right]<\frac{\partial \mu(t)}{\partial t}$. It says that the likelihood of observing a winter period without snow and ice will increase if the relative change in the standard deviation (volatility) of the temperature, weighted with the difference between the critical threshold temperature $x_{c}$ and the mean temperature $\mu(t)$, is less than the change in the mean temperature. Given that temperature is increasing, i.e. $\frac{\partial \mu(t)}{\partial t}>0$, and the mean temperature is lower than the temperature level $x_{\mathrm{c}}$, i.e. $\mu(t)-x_{\mathrm{c}}<0$, the critical point is the direction and how fast the variance is changing relative to the temperature trend. If the variance (standard deviation) is decreasing, it contributes to a reduction of the likelihood of a random snow and ice-free winter, given that $\mu(t)-x_{\mathrm{c}}<0$.

The academic literature in the field of climate is not clear about the future variability in the temperature. Some climatologists find evidence that the volatility will increase, and others find evidence that it will decrease. Meehl et al. (2009) and Rahmstorf and Coumou (2011) argue that the variance in temperature will not change because the frequency of warm extremes will increase and the frequency of cold extremes will decrease, and the net effect is no changes in the variance. Hansen et al. (2012) conclude that the seasonal variation in the winter and summer season in the Northern hemisphere land has increased during the period 1981-2010 
relative to the base period 1951-1980. Huntingford et al. (2013) argue that the volatility in temperature will change on regional level but not globally. Coumou and Robinson (2013) conclude that the variation in temperature on global level will not change. A similar conclusion is drawn by Rhines and Huybers 2013. Rhines et al. (2017) analysed spatial seasonal data on daily time scale, covering $25^{\circ}-55^{\circ} \mathrm{N}$ region of North America, during the period 1979-2014. They conclude that the volatility of the winter temperature (December, January and February) is decreasing. Benestad et al. (2016) draw a similar conclusion based on climate model data that the day-to-day variability in temperature in the Barents region is likely to decrease with higher temperatures. The diverging conclusions are influenced by application of, respectively, different methods, time scale, data from different geographical regions and time periods.

Climate scientists focusing on Norway have not published any analyses about the volatility of the seasonal temperature, except that they have concluded that the frequency of short-term extreme precipitation is expected to increase on top of an increasing temperature trend. Evaluation of the regression model applied on the observed winter temperature data (Table 3) indicates that the residual variance is relatively stable over the period 1916-2015. However, both Hansen's test (significance level of 10\%) and application of the following tests indicate potential changes in the variance: The Goldfeld-Quandt $F$ test (Goldfeld and Quandt 1965), applied on the variance of the residuals of the regression model, indicates that the volatility of the temperature is higher in the period 2005-2015 compared to 1916-2004 ( $F_{9}$, $87=2.39$ and $p$ value $=0.02$ ), but the null hypothesis of equal variance cannot be rejected if the strong effect from the low winter temperature in 2010 is absorbed by an indicator variable in the model $\left(F_{8,86}=1.30\right.$ and $p$ value $\left.=0.26\right)$. Quantile regression (95th and the 5 th percentiles) supports the result. It indicates that the spread of the winter temperature has increased or shifted in the period, but if the strong effect from the 2010 observation is absorbed by including an indicator variable in the model, the quantile regression (Koenker and Bessett 1978) shows that the spread between the 95 th and the 5 th percentiles has decreased during 1916-2015. Combination of a Lagrange multiplier test and evaluation of the autocorrelation function of the squared residuals of the temperature model (Table 3) indicate a weak ARCH effect (autoregressive conditional heteroscedastic). A significant ARCH effect implies that the variance of the disturbances of the temperature sequence can be modelled as an autoregressive moving average-process (ARMA). An ARCH model (Engle 1982) of order four was estimated. The null hypothesis of no systematic variance pattern was close to being rejected, given a conventional significance level of 5\%; $F_{4,92}=2.104$ and $p=0.087$. In summary, the academic literature on climate is not clear whether the volatility of the temperature on seasonal, yearly or longer time scale will change and in what direction. The local time series data sampled in Bergen region indicate that the variance in the winter season 2005-2015 is higher compared to the period 1916-1999, but the result is critically conditioned on the strong effect from the cold winter in 2010.

Figure 4 shows the probability $P(z)$ and associated waiting time (return period) of observing the rare event; "a random year with a winter temperature equal or higher than $7.43{ }^{\circ} \mathrm{C}$ which does not trigger winter operation costs". The probability of the rare event $P(z)$ represents the tail area, i.e. the integral $\int_{7.43}^{+\infty}(2 \pi)^{-\frac{1}{2}} \exp \left(-\frac{1}{2} z^{2}\right) d z$, of the standard normally distributed variable $z(t)=\frac{x_{\mathrm{c}}-\mu(t)}{\sigma(t)}$. The tail area is approximated by a function derived by Choudhury (2014). Two alternative temperature trajectories and two levels of volatility of the temperature are combined. The black solid and dashed lines show the probability and the waiting time of the rare 
event given that the mean temperature increases by $0.0091{ }^{\circ} \mathrm{C} /$ year, i.e. $\frac{\partial \mu(t)}{\partial t}=0.0091$, while the red solid and dashed lines illustrate the probability and waiting time when the mean temperature increases by $0.0392{ }^{\circ} \mathrm{C} /$ year. The linear trend $0.0392{ }^{\circ} \mathrm{C} /$ year corresponds to the (median) development projected by RCP8.5 scenario based on 10 Euro-CORDEX climate scenarios (Hanssen-Bauer et al. 2015, Table A.5.2.2 p. 150). The RCP8.5 scenario has a yearly increase in temperature that is over four times faster than the estimated, local temperature trend in the winter period in Bergen (see Table 3). Two different levels of standard deviation are applied to illustrate the strong effect the volatility has on the likelihood of the rare event. The solid red and black lines apply $1.22{ }^{\circ} \mathrm{C}$ as the standard deviation, while the dashed red and black lines apply $0.88{ }^{\circ} \mathrm{C}$ as the standard deviation. The estimate of 0.88 is derived from the regression model based on local data from 1916 to 2015 (Table 3). Same coloured lines have identical trend, and a comparison of them shows the impact different volatility levels have on the likelihood of the defined rare event. Different coloured lines with identical style have the same volatility, and a comparison of them shows the impact different long-term temperature trends have on the likelihood and waiting time of the rare event.

The red lines are based on the RCP8.5 scenario - also called the business as usual scenario. The red solid line shows, e.g. that the waiting time of a snow-free winter is reduced from 60 to 20 years by about 2035 due to the temperature increase of $0.0392^{\circ} \mathrm{C}$ per year. If the volatility is reduced by $28 \%$, i.e. from 1.22 to $0.88^{\circ} \mathrm{C}$, the red dashed line shows that the waiting time of 20 years in 2035 is realized 10 years later - about 2045. The black solid line shows that the waiting time is reduce from 60 years in 2015 to 20 years about 2085 , given the local estimated temperature trend $0.0091{ }^{\circ} \mathrm{C} /$ year and a volatility of $1.22{ }^{\circ} \mathrm{C}$. Figure 4 shows clearly that the likelihood and waiting time of the rare event are strongly affected by the size of the long-term temperature trend and the volatility. See Online Resources Fig. 3 which illustrates the rare event analysis in a 3D-figure.

\section{Projection of the winter operation costs}

Figure 5 shows how long- and short-term climate change affect the winter operation costs in the period 1993-2106. The graph on the top left shows the observed and projected winter temperature. The historical observational, local temperature data cover the period 1993-2015, while the simulated data cover the period 2016-2106. The trajectory of the temperature is modelled as a sum of two components, respectively, a short- and long-term component, and the
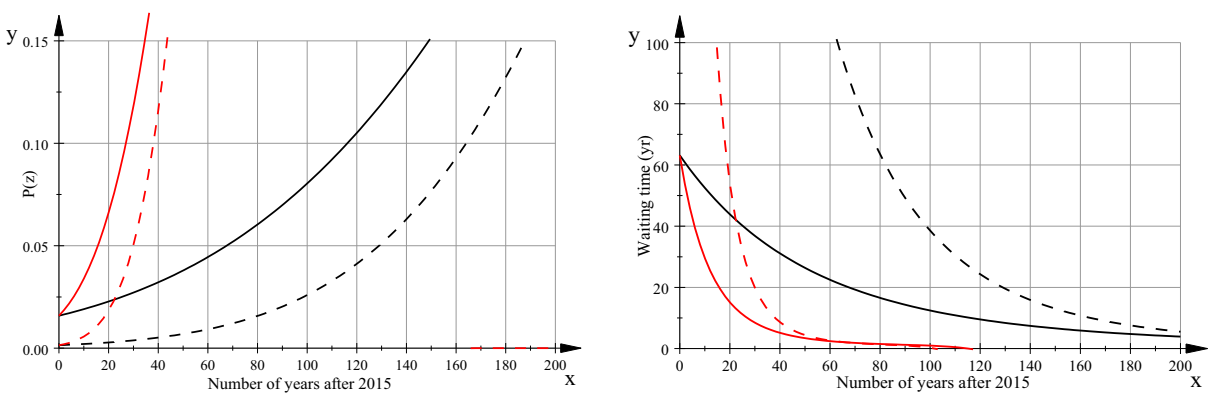

Fig. 4 Climate change scenarios and change in probability and waiting time (return period) for a year without winter operations in Bergen. Four scenarios are illustrated. Black lines show scenarios where the temperature increases by $0.0091{ }^{\circ} \mathrm{C} /$ year and red lines show scenarios based on the RCP8.5 scenario where the trend is $0.0392{ }^{\circ} \mathrm{C} /$ year. Solid lines have $1.22{ }^{\circ} \mathrm{C}$ as the standard deviation per year and dashed lines have $0.88^{\circ} \mathrm{C}$ 

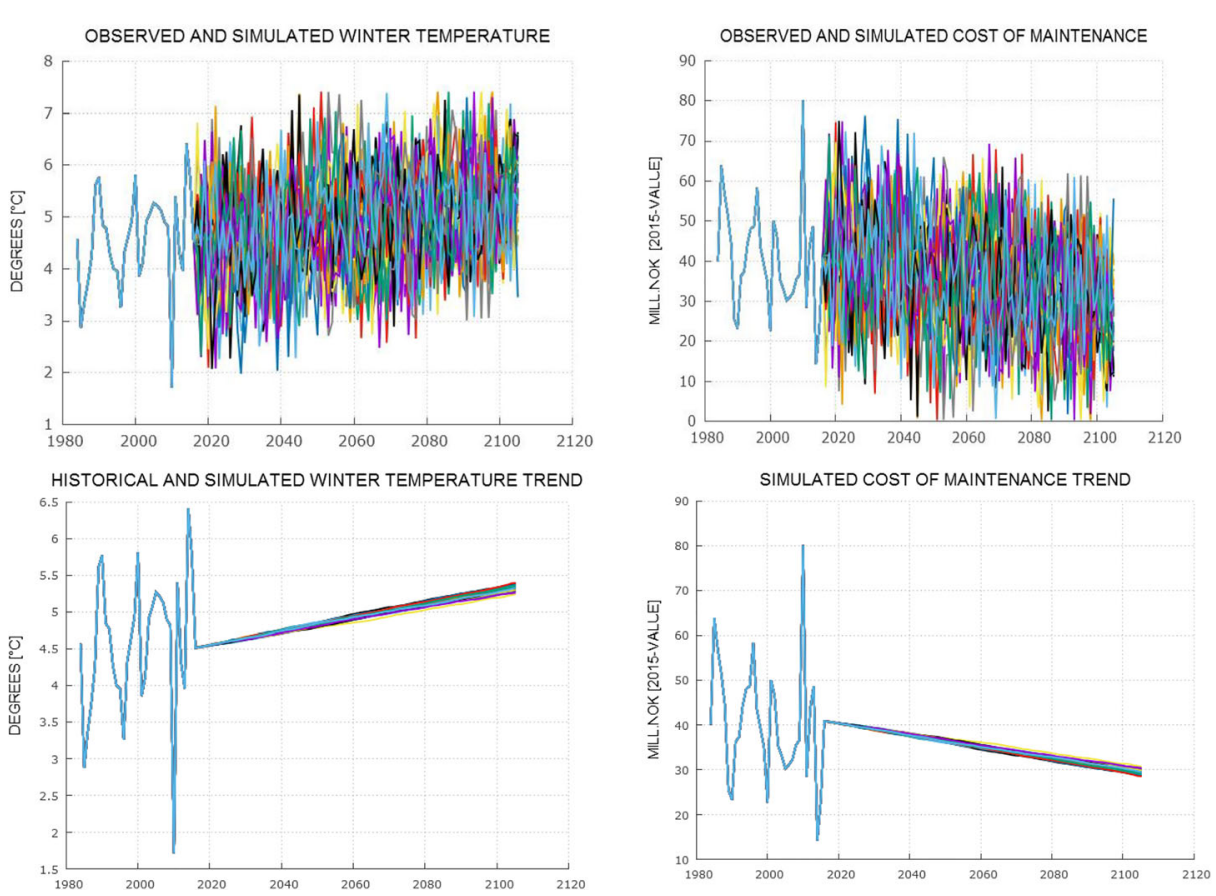

Fig. 5 Simulated development of winter operating costs as a function of a general, short- and long-term increase in the local temperature for the period 2015-2106. The graph (a) on the top left shows the variation in winter temperature caused by the sum of respectively, the short-term variation in temperature and the stochastically, varying, long-term temperature trend. The uppermost, right graph (b) depicts the development of costs given the short and long-term variation in winter temperature. Graphs (c) and (d) show the long-term development in winter temperature and winter maintenance costs where the short-term, stochastic variation in temperature is not included

process is modelled as a trend-stationary realization of the temperature which means that temperature level does not drift away from the long-term trend. The short-term, "noise"component $\varepsilon_{t}$ varies stochastically and independently around the long-term trend component with expectation (mean) equal zero and standard deviation equal $0.88{ }^{\circ} \mathrm{C}$, i.e. $\varepsilon_{t} \sim N(0,0.88)$. The short-term volatility of 0.88 is the standard deviation of the residual of the temperatureregression model presented in Table 3 and Fig. 3. The long-term temperature component is the estimated trend presented in Table 3. The trend coefficient $\beta$ is modelled as a deterministic trend $0.0091^{\circ} \mathrm{C} /$ year with a normally and stochastically distributed noise component $\gamma_{t}$ with expectation equal zero and standard deviation equal 0.003041 , i.e. $\gamma_{\tau} \sim N(0,0.003041)$. By integrating the variation $\gamma_{t}$ in the model, the uncertainty associated to the trend component $\beta$ is internalized in the model. The simulated temperature (see graph on the top left) is based on the following model $x_{t}=x_{0}+\beta t+\sum_{t}^{T} \gamma_{t}+\varepsilon_{t}$, where $t=0,1,2, \ldots, T, \gamma_{t} \sim N(0,0.003041)$ and $\varepsilon_{t} \sim N(0,0.88) . t=0$ represents the starting point in 2015 where $x_{t}=x_{0}=4.65^{\circ} \mathrm{C}$ and $\gamma_{0}=0$, $\varepsilon_{0}=0$. The estimated cost-temperature model, $C_{t}=104.13-14.01 x_{t}$, is applied in "transforming" temperature to costs where $x_{t}$ is the simulated temperature at time point $t$. The graph on the top right shows the variation in the maintenance costs caused by the sum of, respectively, the short-term variation in temperature and the long-term temperature trend. The graph on the bottom left shows the long-term trend. The graph in the bottom right of Fig. 5 
shows how only the long-term temperature trend influences the long-term maintenance costs in the period 2015-2106.

The simulations presented in Fig. 5 show that the short-term, random variation in the winter temperature is of great significance and determines a relatively large proportion of the total year-to-year variation in winter operating costs. Observational data of winter costs in the period 2005-2015 show that the variation is large and making it difficult to see by visual inspection how the long-term trend in temperature affects the winter costs. Another interesting discovery is that the simulations show that there will be considerable variation in costs in the future, and it will take many years before the need for winter operations falls away even though the overall long-term temperature trend is positive. According to the simulations, the frequency of low maintenance costs will increase over time due to the expected long-term increase in temperature. The increase in the frequency of such events is dependent on how fast the temperature increases and of changes in the volatility.

\section{Conclusion and discussion}

The objective of the article is to analyse the impact of climate change on the winter road maintenance costs and the rare event of snow-free winter in Bergen - the second largest city in Norway. The analysis applies multivariate regression methodology, Monte Carlo simulations and mathematics.

The analysis shows that increasing temperatures have a significant negative effect on the winter road maintenance costs. The statistical model predicts that the costs are reduced by about NOK 14 million if the mean winter temperature increases by $1{ }^{\circ} \mathrm{C}$. Application of the model shows that an increase in the mean temperature in Bergen by as much as $2.5^{\circ} \mathrm{C}$, relative to the temperature level in 2005-2015, will give a mild state of climate with expected winter operation costs close to zero. Norwegian climate scientists project that the mean temperature in western Norway will increase in the winter and autumn by between 1.65 and $2.35^{\circ} \mathrm{C}$ by 2060 and between 1.3 and $5.3{ }^{\circ} \mathrm{C}$ by 2100 relative to the level in 1971-2000. The projections depend on the emission scenario. The simulations and the rare event analysis show that the long-term effects will gradually become more visible compared to the present, observed natural and short-term variation in climate.

The analysis shows that the variance (volatility) of the temperature and temperature trend have a strong effect on the profile of the winter and for the likelihood of rare events. The article shows that long-term, structural changes in climate change the probability distribution of climate states. The analysis uses two levels of volatility to illustrate the impact on the likelihood and corresponding waiting time (return period) of a random year without winter road maintenance. The analysis shows (see Fig. 4) that the larger the volatility of the temperature is, the higher is the likelihood of a year without winter costs, and equivalently, a reduction in the volatility reduces the likelihood of a future winter without maintenance costs, given that all other factors are constant. An interesting result of the analysis shows that even though the temperature has a positive trend, the effect of a reduction in the volatility can extend the waiting time of a rare year without winter maintenance costs. Statistical analysis of the local time series data indicates that the variance in the winter season 2005-2015 is higher compared to the period 1916-2004, but the result is critically conditioned on the strong effect from the cold winter in 2010. Scientific literature shows that there is a lack of consensus among the climatologists whether the future volatility will change and in what direction. 
The scenario analysis applied the estimated, historical local temperature trend of $0.0091{ }^{\circ} \mathrm{C} /$ year, and it shows how the long-term development of the local temperature influences the costs. However, Hanssen-Bauer et al. (2015) climate model-based projection of the temperature trend at the west coast of Norway is over four times larger in the business as usual scenario than the estimate of the local temperature trend. If the temperature increases by as much as $0.0392{ }^{\circ} \mathrm{C}$, it will change the development of the winter operating costs significantly, and by about 2100 , it is highly likely that the temperature would have reached a level that implies no snow and ice to remove from the roads.

It is rational that the society adapt to climate changes. Increasing temperatures lead to the long-term to cost reduction, and past economic resources tied up in winter operations, can gradually be transferred and applied in producing other public goods and services. However, if the volatility of the weather in the winter period increases, it can influence on the necessity for investment in extra capacity to handle periods with large amounts of snow. It is to expect that the more volatile and chaotic the weather is, the more difficult it is to "find" the optimal road maintenance capacity. A change in the volatility will change the exposition of risk, and it will influence on the economic incentive to invest in long-lasting winter maintenance machinery. On the other hand, the slower the process of climate change is, the easier it is for the decision-makers to adjust the capacity without losing money. Climate change is also expected to change the frequency of traffic accidents on the roads and deaths rate. These issues are topics for further research, and they are also relevant for the insurance companies.

The local temperature trend is estimated to $0.0091{ }^{\circ} \mathrm{C} /$ year. The estimate is statistically valid, but the estimate is not necessarily based on the most valid model. Further research should consider alternative models because the temperature process indicates a stepwise, non-linear pattern. There is no significant temperature trend in the period 1940-1980 and neither in the period 2005-2015. This pattern could indicate a non-linear process due to for example multidecadal oscillations. Estimation of alternative models is also a topic for further research.

The analysis is based on aggregated data, i.e. the cost data are aggregated, the temperature data are the average of 7 months and precipitation is the sum of 7 months. The effect of aggregation and averaging represent a potential loss of information about the dynamics between the variables. These levels of measurement could also have implication for the calculation of probabilities of rare events and for the simulations. Further research in this field can use disaggregated data, e.g. on monthly time scale.

The analysis provides for the first time the municipality of Bergen and its inhabitants with information about the relationship between climate and winter road maintenance costs. In that respect, the analysis fills a knowledge gap and it is a contribution in the field of climate services. The analysis contributes with information how winter operations are likely to develop in the long term if the temperature changes in a direction that climate scientists project according to their scenarios. The statistical models can help to quantify the amount of economic and material resources needed for this purpose, and the models contribute to better long-term planning, even though the year-to-year variation is large. The analysis can motivate the administration to cooperate with climate scientists and provide researchers with more differentiated and disaggregated data which are a precondition for developing more precise models in forecasting regional winter maintenance costs. 
Acknowledgements I would like to thank senior scientist Iselin Medhaug, ETH Zürich, Department of Environmental Systems Science, Institute for Atmospheric and Climate Science, Switzerland; Professor Erling Moxnes, Department of Geography, University of Bergen, Norway; senior scientist Alastair D. Jenkins, Geophysical Institute, University of Bergen; and four reviewers for valuable comments and suggestions.

Funding Information Open Access funding provided by Western Norway University Of Applied Sciences.

Open Access This article is licensed under a Creative Commons Attribution 4.0 International License, which permits use, sharing, adaptation, distribution and reproduction in any medium or format, as long as you give appropriate credit to the original author(s) and the source, provide a link to the Creative Commons licence, and indicate if changes were made. The images or other third party material in this article are included in the article's Creative Commons licence, unless indicated otherwise in a credit line to the material. If material is not included in the article's Creative Commons licence and your intended use is not permitted by statutory regulation or exceeds the permitted use, you will need to obtain permission directly from the copyright holder. To view a copy of this licence, visit http://creativecommons.org/licenses/by/4.0/.

\section{References}

Andersson AK, Chapman L (2011a) The impact of climate change in winter road maintenance and traffic accidents in West Midlands, UK. Accid Anal Prev 43(1):284-289. https://doi.org/10.1016/j.aap.2010.08.025

Andersson AK, Chapman L (2011b) The use of a temporal analogue to predict future traffic accidents and winter road conditions in Sweden. Meteorol Appl 18:125-136. https://doi.org/10.1002/met.186

Akaike H (1973) Information theory and an extension of the maximum likelihood principle. In: Petrov BN, Csaki F (eds) 2nd International Symposium on Information Theory. Akademiai Kiado, Budapest, pp 267-281

Arent DJ, Tol RSJ, Faust E, Hella JP, Kumar S, Strzepek KM, Tóth FL and Yan D (2014) Key economic sectors and services. In: Climate Change 2014: Impacts, adaptation, and vulnerability part a: global and sectoral aspects. Contribution of Working Group II to the Fifth Assessment Report of the Intergovernmental Panel on Climate Change [Field CB, Barros VR, Dokken DJ, Mach KJ, Mastrandrea MD, Bilir TE, Chatterjee M, Ebi KL, Estrada YO, Genova RC, Girma B, Kissel ES, Levy AN, Mac Cracken S, Mastrandrea PR, White LL (eds.)]. Cambridge University Press, Cambridge, United Kingdom and New York, 659-708

Benestad ER, Parding KM, Mezghani A (2016) Climate change and projections for the Barents region: what is expected to change and what will stay the same? Environ.Res.Lett. 11(2016):054017. https://doi. org/10.1088/1748-9326/11/5/054017

Choudhury A (2014) A simple approximation to the area under standard normal curve. Mathemat Statist 2(3): 147-149

Coumou D, Robinson A (2013) Historic and future increase in the global land area affected by monthly heat extremes. Environ Res Lett 8:034018

Dickey D, Fuller WA (1979) Distribution of the estimators for autoregressive time series with a unit root. J Am Stat Assoc 74(366):427-431

Engle RF (1982) Autoregressive conditional heteroscedasticity with estimates of the variance of United Kingdom inflation. Econometrica 50:787-1007

Førland, EJ, Skaugen TE, Benestad RE, Hanssen-Bauer I, Tveito OE (2004) Variations in thermal growing, heating, and freezing indices in the Nordic Arctic, 1900-2050, Arct Antarct Alp Res, Vol. 36, No. 3, 2004, pp. 346-355

Goldfeld S, Quandt R (1965) Some tests for homoscedasticity. J Am Stat Assoc 60(1965):539-547

Hanbali RM (1994) Economic impact of winter road maintenance on road users. Transport Research Record. http:/onlinepubs.trb.org/Onlinepubs/trr/1994/1442/1442-018.pdf

Hanssen-Bauer I, Førland EJ, Haddeland I, Hisdal H, Mayer S, Nesje A, Nielsen JEØ, Sandven S, Sandø AB, Sorteberg A, Ådlandsvik B (eds.), (2015) Klima i Norge 2100 - Kunnskapsgrunnlag for klimatilpasning Oppdatert i 2015, NCCS-report no.2/2015. In Norwegian: Climate in Norway 2100 - a knowledge base for climate adaptation. [Norwegian Environmental Agency] Miljødirektorat (http://www.miljodirektoratet. no/en/)

Hanssen-Bauer I, Førland EJ, Haddeland I, Hisdal H, Mayer S, Nesje N, Nielsen JEØ, Sandven S, Sandø AB, Sorteberg A, Ådlandsvik B (eds.) (2017) Climate in Norway 2100-a knowledge base for Climate 
Adaptation. NCCS-report no.1/2017. ISSN \# 2387-3027. [Norwegian Environmental Agency] Miljødirektorat. www.miljodirektoratet.no/M741

Hansen BE (1992) Testing for parameter instability in linear models. J Policy Model 14:517-533

Hansen J, Sato M, Ruedy R (2012) Perception of climate change. Proc Natl Acad Sci U S A 109:E2415-E2423. https://doi.org/10.1073/pnas.1205276109

Hitz S, Smith J (2004) Estimating global impacts from climate change. J Global Environ Change 14:201-218. https://doi.org/10.1016/j.gloenvcha.2004.4.010

Huntingford C, Jones PD, Livina VN, Lenton TM, Cox PM (2013) No increase in global temperature variability despite changing regional patterns. Nature 500:327-330

IPCC (2014) In: Team CW, Pachauri RK, Meyer LA (eds) Climate Change 2014: synthesis report. Contribution of Working Groups I, II and III to the Fifth Assessment Report of the Intergovernmental Panel on Climate Change. IPCC, Geneva

Iribarne JV, Godson WL (2013) Water-air systems $\S 4.8$ Clausius-Clapeyron equation. In: Atmospheric Thermodynamics. Springer, Berlin, p 60

Iversen T, Bentsen M, Bethke I, Debernard JB, Kirkevag A, Seland Ø, Drange H, Kristjansson JE, Medhaug I, Sand M, Seierstad IA (2013) The Norwegian Earth System Model, NorESM1-M - part 2: climate response and scenario projections. Geosci Model Dev 6:389-415, www.geosci-model-dev.net/6/389/2013/. https://doi.org/10.5194/gmd-6-389-2013

Jarque C, Bera AK (1981) Efficient tests for normality, homoscedasticity and seral independence of regression residuals: Monte Carlo evidence. Econ Lett 7(4):313-318. https://doi.org/10.1016/0165-1765(81)90035-5

Koenker R, Bessett G (1978) Regression Quantiles. Econometrica 46:33-50

Koetse MJ, Rietveld P (2009) Impacts of climate change and weather on transport: an overview of empirical findings. J Transport Res Part D 14:205-221

Larsen PH, Goldsmith S, Smith O, Wilson ML, Strzepek K, Chinowsky P, Saylor B (2008) Estimating future costs for Alaska public infrastructure at risk from climate change. J Global Environ Change 18:442-457. https://doi.org/10.1016/j.gloenvcha.2008.03.005

Lorentzen T (2014) A statistical analysis of sea temperature data. An example from the Norwegian coast. Theoretical Applied Climatology. Springer-Verlag, Wien. https://doi.org/10.1007/s00704-014-1119-x

Luterbacher J, Dietrich D, Xoplaki E, Grosjean M, Wanner H (2004) European seasonal and annual temperature variability, trends, and extremes since 1500. Science 3003(5663):1499-1503

McKinnon KA, Stine AR, Huybers P (2013) The spatial structure of the annual cycle in surface temperature: amplitude, phase, and Lagrangian history. J Clim 26(20):7852-7862. https://doi.org/10.1175/JCLI-D-13000211.1

Meehl G, Tebaldi C, Walton G, Easterling D, McDaniel L (2009) Relative increase of record high maximum temperatures compared to record low minimum temperatures in the U.S. Geophys Res Lett 36:L23701. https://doi.org/10.1029/2009GL040736

Medhaug I, Stolpe MB, Fischer EM, Knutti R (2017) Reconciling controversies about the global warming hiatus. Nature 545:4. https://doi.org/10.1038/nature22315

Norges Bank (2019) Information about the exchange rate between Norwegian Krone (NOK) and foreign currencies see: http:/www.norges-bank.no/en/Statistics/exchange_rates/

Norwegian Meteorological Institute: Climate data are downloaded from https://www.met.no/en/weather-andclimate

Park BJ, Kim YH, Seung-Ki M (2018) Anthropogenic and natural conditions to the lengthening of the summer season in the northern hemisphere. Am Meteorol Soc 31:6803-6819. https://doi.org/10.1175/JCLI-D-170643.1

Rahmstorf S, Coumou D (2011) Increase of extreme events in a warming world. Proc. Natl. Acad. Sci. USA, 108, 17 905-17 909, doi:https://doi.org/10.1073/pnas.1101766108

Ramsey JB (1969) Test for specification error in classical linear least squares regression analysis. J Royal Statistic Soc B 31:350-371

Reiss RD, Thomas M (2001) Statistical analysis of extremes values with application to insurance, finance, hydrology and other fields, 2nd edn. Birkhauser Verlag AG, Basel

Rhines A, Huybers P (2013) Frequent summer temperature extremes reflect changes in the mean, not the variance. Proc Natl Acad Sci U S A 110:E546

Rhines A, McKinnon KA, Tingley MP, Huybers P (2017) Seasonally resolved distributional trends of North American temperatures show contraction of winter variability. Am Meteorol Soc. https://doi.org/10.1175 /JCLI-D-16-0363.1

Sherif A, Hassan Y (2014) Modelling pavement temperature for winter maintenance operations. Can J Cic Eng 31:369-378. https://doi.org/10.1139/L03107 
Stern N (2006) The economics of climate change - the Stern Review. Cambridge University Press, Cambridge Stine AR, Huybers PJ, Fung IY (2009) Changes in the phase of the annual cycle of surface temperature. Nature 457:435-440. https://doi.org/10.1038/nature07675

Stine AR, Huybers PJ (2012) Changes in the seasonal cycle of temperature and atmospheric circulation. J Clim 25(21):7362-7380. https://doi.org/10.1175/jcli-d-11-00470.1

Sørland LS (2015) Monsson low-pressure systems - the precipitation response to atmospheric warming. Dissertation for the degree of philosophiae doctor $(\mathrm{PhD})$. University of Bergen, Norway

Tol SJR (2018) Review of environmental economics and policy, Volume 12, Issue 1, Winter 2018, Pages 4-25, https://oi.org/10.1093/reep/rex027

United Nations (2015) Paris Agreement, FCCC/CP/2015/L.9/Rev.1. UNFCCC Secretariat, Retrieved 12 Dec. 2015. http://unfecc.int/files/essential_background/convention/application/pdf/english_paris agreement.pdf

White H (1980) A heteroscedastic-consistent covariance matrix estimator and a direct test for heteroscedasticity. Econometrica 48:817-838

Wichers CR (1975) The detection of multicollinearity: a comment. Review of Economics and Statistics. 57(3): 366-368. JSTORE. 1923925

Publisher's note Springer Nature remains neutral with regard to jurisdictional claims in published maps and institutional affiliations. 